\title{
La segunda instancia: Una probabilidad de la sentencia en mínima cuantía*
}

\author{
Orlando Gilbert Hernández Montañez**
}

Fecha de recepción: 28 de noviembre de 2016

Fecha de aprobación: 12 de octubre de 2017

\section{RESUMEN}

Se describen algunas teorías de la argumentación jurídica, insumo para los jueces en la disciplina diaria de tomar decisiones; un punto de vista que, para sus destinatarios, puede ser consecuente con una posición recriminada o aceptada, por cuanto, en un momento dado, se podrían afectar intereses y principios fundamentales a la hora de versar sobre derechos patrimoniales derivados de un conflicto.

De antaño, se ha mirado con somero detenimiento el laborío judicial de los administradores de justicia frente a esa sacramental decisión última, que si bien no constituye un cierre de instancia, sí lo es, en algunos eventos; en un escenario de complejidad procedente de la correcta aplicación del derecho al caso particular o, dicho en otras frases, de la subsunción del supuesto fáctico en la norma; se aportan o generan cambios de interpretación, argumentación y aplicación de la ley, y de contera se brinda una respuesta en socorro de las exigencias invo-

* Este escrito se origina en las pautas elaboradas por el Dr. Enoc Francisco Morán Torres, profesor de Teoría del Derecho en la Universidad de Baja California - Tepic-Nayarit (México). El Artículo es producto del proyecto de investigación de la tesis doctoral del autor, gestionado en la Universidad de Baja California - Tepic-Nayarit (México). DOI: http://dx.doi.org/10.15332/s1909-0528.2018.0001.07

** Especialista en Derecho Constitucional, Procesal y Probatorio, Juez Civil del Circuito de Bogotá D.C., postulante a doctorando en Derecho de la Universidad de Baja California, Tepic - Nayarit, México, Código Postal: 111161, orlandogilbert@hotmail.com. 
cadas por los litigantes o terceros intervinientes. También, se abordarán los efectos jurídicos de la sentencia, como resolución que trasciende de lo judicial a lo social (Ezquiaga Ganuzas, s.f.), con ánimo de afrontar la realidad de la comunidad al querer defender sus puntos de vista y llevar a debate las posiciones apoyadas en las múltiples teorías.

Se evaluará la catadura comportamental de resorte del juez en casos donde las pretensiones patrimoniales no excedan los topes de la mínima cuantía, pero que, al momento de adoptar su decisión, se demuestra una inflación derivada de una indemnización de perjuicios, actualización de sumas, compensación, el pago de frutos o mejoras, etcétera, visualizándose la posibilidad de abrir la puerta de un segundo evaluador en orden jerárquico, cuando no se comparte la postura argumentativa y, sin embargo, se restringe su conocimiento dado el quantum de la pretensión económica inicial que por obra de la indexación o por algún otro ardid supera los lindes pecuniarios primigenios para el devenir procesal.

Palabras clave: interpretación jurídica, constitucionalismo contemporáneo, indexación, sentencias, derecho sustancial, casos difíciles.

\section{Abstract}

Some theories of juridical argumentation are described, an input for judges in the daily discipline of making decisions; a point of view which, for its addressees, may be consistent with a recriminated or accepted position, since, at any given moment, fundamental interests and/ or principles could be affected when dealing with economic rights derived from a conflict.

Of old, the judicial work of the administrators of justice in front of this sacramental final decision, which although it does not constitute a closure of instance, if it is, in some events has been looked at with a brief attention, in a scenario of complexity arising from the correct application of the right to the particular case or, in other words, from the subsumption of the factual assumption in the norm; they contribute or generate changes in interpretation, argumentation and application of the law, and a response is provided in response to the demands invoked by the litigants or intervening third parties. Also, the legal effects of the sentence, as a resolution that goes beyond the judicial to the social (Ezquiaga Ganuzas, s.f.), will be dealt with, in order to confront the reality of the community by wanting to defend their points of view and bring to the debate the positions supported in the multiple theories. 
The judge's behavioral pattern of spring will be evaluated in cases where claims for assets do not exceed the limits of the minimum amount, but at the time of making their decision, inflation is shown as compensation for damages, updating sums, compensation, the payment of fruits or improvements, etc., visualizing the possibility of opening the door of a second evaluator in hierarchical order, when the argumentative position is not shared and yet, their knowledge is restricted given the quantum of the initial economic pretension that by the work of indexation or some other scheme, exceeds the primal pecuniary boundaries for procedural becoming.

Keywords: legal interpretation, contemporary constitutionalism, indexing, sentences, substantive law, difficult cases.

\section{INTRODUCCIÓN}

En mi tarea cotidiana de aplicar el derecho encuentro decisiones que pudieron tener un final diferente, en términos sustantivos, sin embargo, por su connotación limitativa por la cuantía tan solo constituyen una decisión más en los anaqueles de las células judiciales y un desdeño de quien resultó vencido en el escenario judicial.

Es por ello que este artículo busca abrir la posibilidad, por supuesto, dadas unas precisas condiciones, de que ciertos asuntos de trámite en única instancia tengan la factibilidad del recurso de apelación, a la luz de entramados filosóficos y procurando, ante todo, una dispensa de justicia eficaz, adecuada y cumplidora de los fines de un Estado social de derecho, pero por sobre todo una mirada protectora por parte de las instituciones jurídicas respecto de su beneficiario último, el ciudadano de a pie.

Para el estudio y desarrollo de esta investigación, desde la metodología cualitativa, se ha estimado la utilización de varios métodos de investigación científica (Huertas y Otros, 2018) para recolectar la información necesaria, como el método analítico y descriptivo. 


\section{LA ARGUMENTACIÓN JURÍDICA}

El Doctrinante Haba ha manifestado que las tesis realistas implican negar que los jueces pueden "justificar" sus sentencias (Haba, 2011). Al respecto, el profesor Atienza, ha considerado que la postura de autores realistas, como Haba, lleva necesariamente a sostener que los jueces no pueden propiamente (al menos en muchos casos) justificar sus decisiones; y que lo anterior llevaría a que el Derecho estaría gravemente indeterminado porque las decisiones judiciales dependen de juicios de valor que consisten, según Haba en actitudes, en emociones que, en sentido estricto, no son susceptibles de enjuiciamiento racional ${ }^{1}$ (Atienza, 2013)

En este orden de ideas, Haba en debate con Atienza, ha sostenido:

"Considerando la inocuidad de términos como "razonable", para determinar realmente los contenidos decisivos de las sentencias: ¿quiere decir que, si eso es verdad, tal comprobación "lleva necesariamente a sostener que los jueces no pueden propiamente (al menos en muchos casos) justificar sus decisiones"? Contesto: ¡ni por asomo pienso así! Pero Atienza dice que sostengo tal cosa, o que en todo caso ello estaría implicado necesariamente en mis afirmaciones (me dé cuenta o no, y lo quiera o no lo quiera): “... porque las decisiones judiciales dependen de juicios de valor que... en sentido estricto, no son susceptibles [según H.] de enjuiciamiento racional". (Haba, 2011, p. 34).

En realidad, la discusión se centró en lo que pudo o no afirmar Haba, pero lo rescatable de esa presumible equivocación estriba en que este le atribuye semejante dislate sobre la base de dos decretos lingüísticos imaginados por Atienza, v.gr., las expresiones "juicios de valor" y "justificar"; según Atienza, Haba entiende estas dos formulaciones desde un concepción restringida, esto es, juicios de valor pura y simplemente ciertas "emociones" sin más; en tanto, "justificar" como prescindir de juicios de valor al fundamentar.

1 Al respecto es importante no olvidar la noción de lo que parte de la Doctrina ha comprendido como activismo judicial, esto es, aquel abuso de poder sin supervisión (Bahamon \& Gomez, 2017) 
Todo ello lleva a Haba a emitir varias aclaraciones. La primera y más apreciable es que él es de la teoría de que los juicios de valor que realizan los jueces en sus sentencias sí son susceptibles de enjuiciamiento racional.

En segunda medida, marca la diferencia entre juicios de valor categóricos y juicios de valor instrumentales, pues, Atienza "echa todo en una misma bolsa (juicios de valor in genere)". Y se refirió a los juicios de valor instrumentales porque entiende que ellos constituyen el eje central y práctico de las discrepancias valorativas discutidas en los tribunales, señalando "el verdadero quid de las discusiones son las respectivas consecuencias prácticas - jjuicio instrumental! - que unos contra otros vinculen a los juicios de valor categóricos invocados: 'justicia', 'dignidad' de toda persona humana, 'igualdad' ante la ley, 'interés nacional', 'razonabilidad', 'proporcionalidad'”. Así pues, dice Haba que los juicios de valor, y por supuesto el enjuiciamiento, están sobre el tapete, incluso, expresó: "Si los jueces quieren, ellos sí, 'pueden propiamente (al menos en muchos casos) justificar sus decisiones' de tal manera; como también pueden, por supuesto, razonar de otras maneras (como hacen en general)".

En tercer y último lugar, Haba consideró que Atienza equivocó algunos otros términos lingüísticos cuya comprensión es como sigue:

_“justificar” se le llama al hecho de apoyar las ideas que se presentan a título de razones (fundamentos) (Atienza, 2013)

-“fondo” sirve para calificar lo que cada quien juzgue más importante y decisivo para resolver la cuestión considerada (Atienza, 2013)

Esa discusión entre estos dos intelectuales permite con marcada entonación concluir que las sentencias llevan inherente una serie de axiomas, a la sazón de premisas fácticas y normativas, por lo tanto, la exposición de motivos y argumentaciones están a discrecionalidad del juez por obviedad de cara a un íter probatorio previamente concebido y, desde luego, son susceptibles de ataque, por consiguiente, se participa de la conclusión de Haba, según la cual:

En síntesis.- Los jueces “justifican” sus decisiones, de hecho, tanto si emplean unos argumentos como si emplean otros, y tanto si sus argumentos son vistos como "razonables" (por unos juristas) como si son vistos como "irrazonables" (por otros 
juristas), recurriendo para ello a tales o cuales modelos normativos. Naturalmente, en esto no hay nada que los jueces "no pueden" hacer, tanto si unos teorizadores lo llamen "razonable" como si otros prefieren no sucumbir al encanto retórico de usar como manto persuasivo tal término (Haba, 2011).

En concordancia con lo dispuesto en líneas anteriores, Dworkin ha planteado una teoría normativa que pretende redimir la virtud política; y desde la citada perspectiva, es importante distinguir el principio judicial de integridad, con el papel del juez cuando resuelve casos difíciles, en aras de encontrar la mejor interpretación de la estructura política y de la doctrina jurídica de su comunidad; todo ello a partir de una serie de principios conocidos y aceptados en el contexto social, reflejo de sus derechos y deberes (Bonorino y Peña, s.f.). Al respecto, ha considerado Dworkin que El principio judicial de integridad ordena a los jueces que identifiquen los derechos y deberes jurídicos, en la medida de lo posible, suponiendo que todos ellos fueron creados por un único autor - la comunidad personificada - expresando una concepción coherente de la justicia y la equidad; y Ezquiaga, al respecto ha considerado que el Juez cuando aplica el derecho en su decisión final, favorece, critica, extrae conclusiones, vierte opiniones personales, en definitiva, proyecta en su actividad todas las convicciones, preferencias y opciones. Lo anterior esta en perfecta congruencia con Dworkin, en tanto que el oficio interpretativo realizado por el juez armoniza con una actividad política (Bonorino y Peña, s.f.).

Analizar estos dos supuestos no conlleva nada distinto a advertir una marcada coexistencia en la argumentación del fallo desde un ambiente interpretativo generado por las exigencias de la vida social y ello permite, inexcusablemente, buscar la confirmación de la hipótesis planteada en este trabajo desde la exploración del contexto socio-político del derecho; el juez no puede ser un agente solitario donde sus juicios valorativos graficados en la sentencia se agoten en el conocimiento que de ellos puedan tener sus destinatarios finales, por el contrario, desde su insular perfil las determinaciones asumidas por él deben guardar una correlatividad — de marcación, si se quiere- con el inconsciente colectivo. La sociedad como benefactora de las decisiones judiciales es la que, al final de los días, juzga los aciertos o desaciertos de sus jueces, juezas, magistrados y magistradas. Todo ello permite la imposición de un 
sello atemperado por la ideología dinámica como la llama Wroblewski, compartida en toda su dimensión.

Finalmente, Dworkin planteó un campo de discusión respecto de la tesis de pedigrí, (denominada de esa manera) propuesta por Hart — positivista — cuya teoría parte de que el derecho siempre ha de quedar identificado a través de una regla de reconocimiento como última ratio de validez. Desde la otra orilla, Dworkin, por el contrario, llama principio a una norma que debe ser observada porque es una exigencia de la justicia, de la equidad o de otra dimensión de la moralidad y apoya su hipótesis cuando en algunas comunidades los principios morales tienen fuerza jurídica y lo que los activa como derecho es su verdad (moral) para la resolución de los conflictos, esto es, la aceptación por parte de la colectividad como materialidad, más que su promulgación formal por los entes competentes.

La diatriba propuesta por Dworkin precisamente la ubica en la regla de reconocimiento como personalización del derecho válido, con la que no está de acuerdo; su planteamiento es que si la regla de reconocimiento tiene como propósito identificar las normas de un sistema jurídico, no cumple su cometido, es incapaz de hacerlo, "puesto que no sirve para identificar los ya citados principios" (Jiménez, sf, p. 45) en tanto que ella suministra solo criterios formales de validez, es decir, "criterios relativos al origen o pedigrí de las normas" (Jiménez, s.f., p. 45), en cambio los principios obligan jurídicamente y son parte esencial del derecho. En ese entramado, para Dworkin las reglas, igual que los principios, obligan de la misma manera, considerando que estos existen más allá, o sobre, el derecho. Y esta reyerta llevó a la teoría del 'positivismo suave' caracterizado por comprender que la regla de reconocimiento puede incorporar criterios morales sustantivos de validez jurídica.

\section{LA SENTENCIA COMO ACTO DEFINITORIO}

Empiezo este título parafraseando lo memorado por Hernando Morales Molina al definir la 'Sentencia' como aquella resolución pronunciada “por el juez con aplicación a la ley sobre el punto o cuestión que ante él se controvierta. En cuanto la sentencia resume y concreta la comprobación realizada por el juez sobre los hechos 
y el derecho aplicable, es un acto de inteligencia; pero en cuanto a la voluntad de la ley se concreta en una orden o resolución del juez. La sentencia constituye también un acto de voluntad" y como carácter 'definitivo' cuando el juez resuelve, terminado el proceso y con vista de lo alegado y probado por los litigantes" (Morales, sf, p.56).

En realidad, la sentencia genera una serie de matices para los sujetos procesales y al mismo tiempo representa una decisión que puede favorecer a uno de los litigantes, en tanto, correlativamente, perjudica a otro u otros: imaginemos a la persona que procura que se le reconozca una indemnización derivada del hecho eventual de la responsabilidad civil extracontractual; seguramente la víctima reclama de su victimario un resarcimiento de perjuicios de todo tipo, materiales, morales, daño fisiológico, en fin, pretensiones todas ellas trocadas en números; luego, a ciencia cierta, ese pronunciamiento de instancia (fallo) crea en los pleiteadores un sentimiento de benevolencia o de ansiedad, por cuanto el horizonte de la determinación bien pudo tener un arraigo positivo frente a las súplicas o, por el contrario, fue desestimatoria de las mismas; es más, ello trasciende al escenario personal y torna las ilusiones puestas en el juicio en quimeras, donde solo tiene espacio la mente en cuanto el mandato del juez pudo ser otro y, por qué no, hasta impotencia cuando se está ante un cierre categórico de la instancia donde las objeciones ya no tienen cabida, máxime cuando la cosa juzgada es garantía de la seguridad jurídica y patentiza los fines esenciales del Estado, el orden, la pacífica convivencia y la solución de los conflictos en la vida de relación

Razón tenía la Corte Constitucional ${ }^{2}$ cuando estimó que nuestro Estado debe garantizar el derecho a la dignidad humana en el marco de los procesos judiciales. (Corte Constitucional, 1998), lo cual está en armonía con la doctrina aristotélica; atendiendo a que Aristóteles, cuando reflexionó sobre el ser humano como "animal político", y como consecuencia de ello la obligación del Estado de lograr la mejor organización de comunidad humana en el marco del Derecho Procesal (Gaarder, 1994). Lo dispuesto en líneas anteriores supone el buen funcionamiento de la Administración de

2 Al respecto la profesora Vargas ha considerado que "La jurisprudencia constitucional es considerada como fuente formal y material del derecho en el sistema jurídico colombiano, de ahí procede su fuerza vinculante en las decisiones de las autoridades judiciales y administrativas. Este reconocimiento, derivado de la función judicial de la Corte Constitucional, no se da en la jurisdicción de lo contencioso administrativo, toda vez que el Consejo de Estado no se ha ocupado de una acuciosa expedición, recopilación y publicación de sentencias con carácter vinculante." (Vargas, 2018, p. 119) 
Justicia en cabeza de los jueces de la República, quienes por conducto de sus buenos oficios dirimen los conflictos de intereses, incluso en aquellos eventos donde no existe ley exactamente aplicable al sub examine, pues deben echar mano de las leyes regulatorias de casos o materias semejantes, y en su defecto de la doctrina constitucional y las reglas generales del derecho (Art. $8^{\circ}$ Ley 153 de 24 de agosto de 1887). No se olvide que el juez como órgano de la actividad jurisdiccional del Estado ejerce su función aplicando la norma jurídica al caso concreto, interpretando el sentido, alcance, su finalidad e integrando el orden jurídico.

\section{El PRINCIPIO CONSTITUCIONAL DE LAS DOS INSTANCIAS}

El principio constitucional de las dos instancias está previsto en el artículo 31 de nuestra Carta Política, institución de origen pretérito y de abordaje en múltiples documentos.

Incuestionablemente, las decisiones emitidas por los jueces deben pasar por el escáner de un funcionario de grado superior, necesidad apremiante por cuanto al fin y al cabo se busca generar seguridad jurídica en los asociados frente a cómo se da solución a sus conflictos y, de paso, se le permite conocer a un segundo evaluador el asunto crítico de la contención desde un tamiz de discusión de puntos álgidos. De otra parte, los medios de impugnación, no solo responden a lo que se viene analizando, sino también a la garantía del debido proceso y de suyo, activan el ingrediente 'social' como expresión de un Estado de avanzada hacia las garantías constitucionales dejando de lado la simple retórica, eso sí, sin perder de vista que los principios como los derechos no son absolutos.

Aunado a ello, el recurso de apelación está íntimamente ligado a la regla sugerida por el canon 31 constitucional y por su conducto el proceso se desarrolla en dos grados sucesivos y verticales; casi que la relación entre el proceso y la instancia es igual a la que se presenta entre el todo y la parte o entre continente y contenido; el proceso es el todo y la instancia una fase de este, lo que no obsta para que una instancia constituya todo el proceso o, mejor, el proceso se desarrolle en una sola instancia (Suarez, s.f., p. 44) 
En esa dirección, la Corte Constitucional consideró:

[...] si bien es cierto que el principio de la doble instancia admite excepciones, no lo es menos que la posibilidad de interposición de los recursos consagrados en el ordenamiento es una garantía esencial del debido proceso de raigambre constitucional, comoquiera que los recursos, concebidos como instrumentos de defensa mediante los cuales quien se considere afectado por una decisión judicial o administrativa la somete a nuevo estudio para obtener que se revoque, modifique o aclare, hacen parte de las garantías propias del debido proceso. El artículo 29 de la Constitución exige que todo juzgamiento se lleve a cabo con observancia de la plenitud de las formas propias de cada juicio. Entre éstas, que son señaladas por la ley, está la posibilidad de instaurar recursos contra las determinaciones que se van adoptando en el curso del trámite procesal o al finalizar el mismo (Corte Constitucional, 1994)

En el ámbito de nuestro derecho doméstico y bajo la potestad reguladora atribuida al Congreso — como órgano legislativo - nuestra Corte Constitucional ha defendido la tesis según la cual la restricción en el ejercicio del recurso de apelación no desencadena desigualdad, como tampoco un trato diferenciado y por ende discriminatorio, siempre y cuando se respeten el debido proceso, el derecho de defensa, la igualdad y no se niegue el acceso a la administración de justicia, más aún si con esa limitación se persigue un fin legítimo, razonable y proporcionado.

Así, por ejemplo, en la Sentencia C-365 de 1994 la Corte declaró exequible el artículo 32 de la Ley 81 de 1993 modificatoria del canon 215 del Código de Procedimiento Penal que exigía al apelante la imposición de sustentar el recurso de apelación so pena de declararlo desierto. Se consideró, por razones de economía procesal y de mayor eficiencia en la administración de justicia, la obligatoriedad para el apelante de indicar las que, en su sentir, son las falencias de la decisión impugnada y por ese sendero se le permite al juez superior centrar su análisis en los aspectos relevantes de la apelación, sin dejar de lado aquellos otros factores inherentes a la decisión para emitir su resolución. También se argumentó, entre otras razones, que proceder de tal manera no es atentatorio del derecho sustancial, pues no se conduce a la nugatoria o desconocimiento de los derechos del apelante, contrario sensu, lo impoluto es hacer 
explicita la inconformidad con miras a un mejor análisis acerca del contenido de sus pretensiones y de la providencia misma.

Igualmente, en la Sentencia C-788 de 2002 se analizó la demanda al artículo 392 (parcial) de la Ley 600 de 2000, allí se contenían algunas reglas de control de la medida de aseguramiento y las decisiones que afectan a la propiedad, posesión, tenencia o custodia de bienes muebles o inmuebles, proferidas por el fiscal general de la Nación o su delegado y en uno de sus apartes se estatuyó que las decisiones de cara a tales pronunciamientos "no admiten ningún recurso". La Corporación reflexionó que el principio de las dos instancias no tiene carácter absoluto, en el sentido de que necesariamente toda sentencia o cualquier otra providencia judicial debe ser susceptible de ser apelada o consultada, por cuanto, por expresa autorización del constituyente, el legislador puede consagrar excepciones.

De otro lado, en la Sentencia C-319 de 2013 los accionantes, vía acción pública de inconstitucionalidad, solicitaron la abdicación del artículo 16 de la Ley 393 de julio 29 de 1997 por la cual se desarrolló el artículo 87 de la Constitución Política. Este canon sostiene que las providencias que se dicten en el trámite de la acción de cumplimiento, con excepción de la sentencia, carecen de recurso alguno. Nuevamente, reiteró, las reglas definidas en materia de los límites a la libertad de configuración normativa que tiene el legislador, $v . g r$., el artículo 228 de la norma fundamental, los numerales $1^{\circ}$ y $2^{\circ}$ del artículo 150 de la Constitución Política; por consiguiente, la competencia del legislador es la determinación de los procedimientos y acciones judiciales bajo un margen amplio de configuración, permitiéndole diseñar los trámites que considere más adecuados al cumplimiento de los fines del proceso, posibilidad que incluye privilegiar determinados modelos de procedimiento o incluso prescindir de etapas o recursos en algunos de tales trámites o incluirlos en otros.

Finalmente, en Sentencia C-159 de 2016. A través de la Ley 1564 de 12 de julio de 2012 se importó de la legislación foránea la figura del proceso monitorio, con límites en su desarrollo, ya que el mismo solo resulta aplicable en tratándose de obligaciones dinerarias; estimaron los ciudadanos accionantes que esa premisa limita injustificadamente las otras prestaciones que no son de ese tipo y que tampoco consten en título ejecutivo. En aquel momento, la Corte declaró exequible la norma demandada, en 
primer lugar por ser compatible con la Constitución y en segundo término, porque la misma no impone una restricción injustificada al derecho de acceso a la justicia y a la tutela judicial efectiva.

Razones varias y de todo tipo pueden ajustarse para restringir no solo la apelabilidad de las sentencias, sino también la naturaleza de los procedimientos, circunstancia que no admite discusión, pues, al fin, son potestades dadas por el constituyente al legislador de expedir códigos en todas las materias, de reformarlos y derogarlos.

\section{EL PERJUICIO, SUS LÍMITES Y BONDADES}

En Colombia se implementó un "nuevo" sistema en asuntos civiles, comerciales, de familia y agrarios para la resolución de conflictos, cambiando el prototipo del proceso eminentemente escrito por uno mixto — escrito, oral y por audiencias- . Se buscó de alguna manera restringir libertades, unificar procedimientos, concentrar actos procesales, minimizar tiempos de respuesta y practicidad en las decisiones; hasta un cambio de paradigma en la labor de litigar. No obstante, en cuantías, competencias y sus mínimos casi que reprodujo la norma anterior (Código de Procedimiento Civil), por supuesto con algunos cambios — se abordaran solo aquellos relevantes para darle un espacio de discusión con una postura crítica, racional y contemporánea acorde con el constitucionalismo.

En materia de cuantías, existen tres modalidades, mínima, menor y mayor. La primera, se mira en el artículo 25 del Código General del Proceso (Ley 1564 de 12 de julio de 2012.) y establece: "Cuando la competencia se determine por la cuantía,... Son de mínima cuantía cuando versen sobre pretensiones patrimoniales que no excedan el equivalente a cuarenta salarios mínimos legales mensuales vigentes (40 smlmv)". Al contemplarse como asuntos de ese entorno cuantitativo por lógica consecuencia su tramitación se surte en única instancia a la luz del canon 17 de la norma referenciada, es decir, el recurso de apelación para esas eventualidades está marginado o proscrito.

La forma para establecer la cuantía se delinea en el artículo 26 de la misma codificación, vale acotar: “[...] Por el valor de las pretensiones al tiempo de la demanda, sin 
tomar en cuenta los frutos, intereses, multas o perjuicios reclamados como accesorios que se causen con posterioridad a su presentación". Esto significa, entonces, que el legislador de cara al aspecto cuantitativo en la cuestión le dio un efecto mayúsculo a la presentación de la demanda como mojón a partir del cual las sumatorias futuras no son de relieve para la composición del quantum por el factor objetivo (competencia). Tal vez, como conclusión a priori, se podría sustentar en apoyo a esa fórmula legislativa la dificultad de llevar a futuro operaciones sin una base real; por ejemplo, imaginemos una reclamación de perjuicios provenientes de una responsabilidad civil contractual, detrimento permisible de ser apreciado bajo un medio de prueba de pronunciamiento posterior (juramento). En estas líneas, empero, tal arista de la reclamación tiene lindes perfectamente diferenciados en la jurisprudencia nacional:

[...] hay que recordar que 'cuando se pretende judicialmente el pago de perjuicios, al actor le corresponde demostrar, salvo los casos de presunción de dańo, como ocurre en la cláusula penal y el caso del numeral $2^{\circ}$ del artículo 1617 del Código Civil, la lesión o menoscabo en su patrimonio, bien por una pérdida real y efectiva, ora de una ventaja o garantía, ocasionado por la inejecución o ejecución defectuosa o tardía de las obligaciones del deudor. Significa esto que el dańo susceptible de reparación debe ser "directo y cierto" y no meramente "eventual o hipotético", esto es, que se presente como consecuencia de la "culpa" y que aparezca "real y efectivamente causado". (Corte Suprema de Justicia, 2015)

Entonces, si es difícil establecer los cimientos del daño causado, con mayor razón su cuantía, a lo sumo, por eso, sin temor a equivocación, el legislador desechó solo para efectos del arrojo de la cuantía todas aquellas erogaciones futuras a la presentación de la demanda, por supuesto, ello no quiere decir que el perjuicio anterior a ese acto de postulación se contemple como de fácil demostración, sin embargo, no es lo mismo establecer unas cuantías pasadas a unas expectantes o futuras, independientemente de que el perjuicio penda de prueba o en el itinerario del proceso se cuestione no solo el daño como tal, sino también su cuantificación. Como complemento, en materia de actualización de valores se cuenta con métodos de indexación como forma de repeler la inflación con base en los indicadores económicos, el más usual, el Índice de Precios al Consumidor (IPC). 
Ahora, un medio de prueba que en los últimos tiempos ha tomado fuerza en lo judicial es el juramento estimatorio, no por novedoso, sino debido al auge brindado a partir de la promulgación de la Ley 1395 de 2010 y la forma cambiante de su percepción legislativa.

En el artículo 211 de la referenciada norma se establecía que cuando con la demanda se pretenda el reconocimiento de una indemnización, compensación o el pago de frutos o mejoras se deberá estimar razonadamente bajo juramento en la demanda o petición correspondiente. Dicho juramento hará prueba de su monto mientras su cuantía no sea objetada por la parte contraria dentro del traslado respectivo. El juez, de oficio, podrá ordenar la regulación cuando considere que la estimación es notoriamente injusta o sospeche fraude o colusión.

Mírese, entonces, la expansión al contexto de lo que supone la pretensión de carácter monetario; al respecto es importante anotar que las indemnizaciones en un juicio pueden ser de variada naturaleza, esto es, patrimoniales como no patrimoniales, y su tasación le corresponde a juez; habiéndose acreditado previamente el perjuicio.

$\mathrm{Al}$ respecto, la Corte Suprema de Justicia ha considerado:

[...] por supuesto que las características del dańo, su gravedad, incidencia en la persona, el grado de intensidad del golpe y dolor, la sensibilidad y capacidad de sufrir de cada sujeto, son variables y el quantum debeatur se remite a la valoración del juez, estimando, apropiada la determinación de su cuantía en el marco fáctico de circunstancias, condiciones de modo, tiempo y lugar de los hechos, situación o posición de la víctima y de los perjudicados, intensidad de la lesión a los sentimientos, dolor, aflicción o pesadumbre y demás factores incidentes conforme al arbitrio judicial ponderado del fallador... la reparación del dańo causado y todo el daño causado, cualquiera sea su naturaleza, patrimonial o no patrimonial, es un derecho legítimo de la víctima y en asuntos civiles, la determinación del monto del dańo moral como un valor correspondiente a su entidad o magnitud, es cuestión deferida al prudente arbitrio del juzgador según las circunstancias propias del caso concreto y los elementos de convicción. (Corte Suprema de Justicia, 2009) 
Igualmente, en otra decisión, la Corte Suprema, puntualizo:

El tema que a casación se trae en el cargo sub examine, no ha sido ajeno a los pronunciamientos de esta Corporación, quien de antiguo ha precisado que la fijación del daño moral subjetivo es de exclusivo resorte del juzgador, por lo que mal puede imputarse la violación de la ley sustancial cuando en ejercicio de tal facultad, éste fija prudencial y razonablemente el monto de tales daños (Corte Suprema de justicia, 2007)

Luego, no era acertada la estimación bajo juramento de todo daño, solo el patrimonial y así se corrigió cuando en el inciso 6º del artículo 206 del Código General del Proceso se expresó que "El juramento estimatorio no aplicará a la cuantificación de los daños extramatrimoniales”. Incluso dispuso la discriminación del daño patrimonial para cada uno de los conceptos.

Establecidos estos derroteros, vale la pena acotar la limitación impuesta por el legislador al juez en materia de perjuicios emanados del inciso $5^{\circ}$ de la regla en cita, en cuanto no es posible el reconocimiento del daño por suma superior provenida del juramento estimatorio, con excepción de aquellos de causación posterior a la presentación de la demanda o cuando la parte contraria los objete y refleja la regla: "Serán ineficaces de pleno derecho todas las expresiones que pretendan desvirtuar o dejar sin efecto la condición de suma máxima pretendida en relación con la suma indicada en el juramento". En este último aparte el legislador reconoce que pueden tener existencia material daños futuros.

A modo de cierre, es importante señalar las diferentes postulaciones jurídicas en materia del daño, las cuales deben ser expresiones materializadas en la sentencia como acto determinante, lo que de todas maneras no resultaría del todo posible, si no fuera porque el artículo 16 de la Ley 446 de 1998 marca que "dentro de cualquier proceso que se surta ante la Administración de Justicia, la valoración de dańos irrogados a las personas y a las cosas, atenderá los principios de reparación integral y equidad y observará los criterios técnicos actuariales" y, en todo caso, la regla no hace diferenciación en la fuente de la indemnización. En otros términos, es función del juez ordenar al responsable del daño la reparación a plenitud de la conducta descrita en la norma. 
Postura a tono con la teoría pura del derecho de Hans Kelsen y su tesis del acto antijurídico, definido como la conducta del sujeto contra quien se dirige una sanción, por ende, si la norma consiste en un juicio de valor que relaciona una conducta con una sanción, la conducta del sujeto a la que se imputa la sanción es el acto antijurídico. Pongamos un ejemplo. El artículo 2345 del Código Civil prevé que "el ebrio es responsable del daño causado por su delito o culpa", de ella se pueden extraer las siguientes afirmaciones: (i) la conducta "el daño causado" constituye el acto antijurídico (delito o culpa); (ii) el borrachín tiene el deber jurídico (u obligación jurídica) de responder por sus actuaciones y (iii) la víctima o sus causahabientes tienen el derecho subjetivo de recibir la reparación plena, indistintamente, su origen. Así, sobre el juez recae la obligación de ordenar al demandado la restitutio in integrum a favor del damnificado, es decir, que deberá poner al sujeto (víctima) en un escenario lo más semejante a aquel, en el que se encontraría de no haber sufrido el daño o perjuicio.

\section{UNA MIRADA AUSTERA DE LA CONDENA EN LA SENTENCIA}

Los dos casos a tratar seguidamente, si bien comportan una situación disímil relacionada con los lindes y facultades para el juez al momento de fallar, por cuanto en la especialidad laboral son permisible las facultades ultra y extra petita, no así en materia civil, no solo por los límites informados, a espacio atrás, sino además por el principio de congruencia (Art. 281 CGP); en todo caso, representan una posibilidad de abrir probabilidades de revisión por un juez jerárquico en lo civil.

Caso 1. En demanda ante la jurisdicción ordinaria laboral, los ciudadanos F. V. D. y F. C. G. pretendían el reconocimiento de una partida adicional (por pensión de vejez) en junio de 2014 para este último y para el primero, respecto de los meses de junio de los años 2012, 2013 y 2014 junto con los réditos por mora. Con todo, y al parecer por equivocación, se determinó la cuantía en un valor inferior a 20 salarios mínimos legales mensuales (única instancia). Finalmente, se condenó a la Federación Nacional de Cafeteros de Colombia a pagar, en adelante, "la mesada adicional de junio, en un $100 \%$ ".

La Corte Suprema de Justicia, en sede de tutela, consideró que no obstante haber adelantado el proceso ordinario, como de única instancia, lo cierto es que la condena 
impuesta al interior del mismo, a cada uno de los demandantes, de manera independiente y autónoma, por la proyección futura que implica el pago de las mesadas de junio venideras, supera los 20 salarios mínimos mensuales legales vigentes, lo que implica que el a quo, ha debido garantizar el principio de la doble instancia, concediendo a la parte demandada, la posibilidad de apelar la sentencia dictada en dicho proceso.

Se le ordenó al Juez de conocimiento conceder la posibilidad de interponer el recurso de apelación contra la sentencia dictada al interior del proceso ordinario laboral.

Caso 2. A través de un proceso ordinario laboral promovido por Y. K. N. M. contra C. S. A. Pensiones y Cesantías se solicitó el reconocimiento del valor de las incapacidades laborales por $\$ 5 \% 38.000$, asunto de trámite en única instancia. Empero, para cuando se adoptó la decisión estimatoria, se condenó por una cifra superior a la cuantía asignada para el proceso de mínima cuantía $(20 \mathrm{smlmv})$ y el recurso de apelación fue negado.

En acción de tutela el Tribunal Superior deDistritoJudicial—Sala Laboral—concluyó:

En el presente caso, tal y como quedó reseñado en los antecedentes de la decisión, la sociedad accionante solicitó la protección al derecho fundamental al debido proceso, que consideró, estaba siendo vulnerado por el Despacho judicial accionado que impidió el trámite del recurso de apelación, dentro del proceso ordinario laboral de única instancia que promovió Y. K. N. M.

Sobre el asunto, efectivamente, como lo alegó la activa, la CSJ, en sede de tutela ha considerado que cuando en un proceso ordinario laboral que se tramita por el procedimiento de única instancia, la condena supera el límite de $20 \mathrm{smlmv}$, procede el recurso de apelación a favor de la parte que tiene interés jurídico para ello.

Por consiguiente, como quedó indicado en párrafos anteriores, se revocará el fallo impugnado y se concederá la protección del derecho del derecho fundamental del debido proceso de la sociedad C. S. A. Pensiones y Cesantías, declarando la nulidad, a partir de las actuaciones procesales que se generaron de la sentencia $1^{\circ}$ de octubre de 2015, dentro del proceso ordinario laboral No. 2014-286 en donde fungió como 
demandante, incluso lo actuado dentro del proceso ejecutivo a continuación del proceso ordinario, con el fin de que el Juzgado $2^{\circ}$ Municipal del Pequeñas Causas Laborales de Bogotá, que asumió el conocimiento de los procesos le conceda la oportunidad de interponer el recurso de alzada, por tratarse de un proceso en el que, pese a haber sido tramitado como de única instancia, se profirió sentencia cuyas condenas superan los 20 salarios mínimos mensuales legales vigentes (Tribunal Superior de Distrito Judicial, 2016)

En el ramo civil, como se explicó, existen barreras para el juez a la hora de cuantificar la condena en su fallo, pero también ciertas libertades, igualmente, casos de difícil decisión, de ahí la necesidad y por supuesto la hipótesis resguardada en este artículo: el papel permisible del juez, pese a contar con una decisión en única instancia, de conceder el recurso de apelación, sí y solo sí la condena rebasa los rasgos cuantitativos en esa tipología de asuntos.

La ley civil procesal reclama del juez un pronunciamiento en concreto al momento de dictar sentencia en relación con el pago de frutos, intereses, mejoras, perjuicios u otra cosa semejante por "cantidad y valor determinados" con cifras actualizadas (Art. 283 CGP).

Sobre el particular la jurisprudencia ha puntualizado:

[...] para que la indemnización sea completa, se deben tener en cuenta las condiciones particulares en que se halla el damnificado y la magnitud del dańo resarcible tal como se encuentre al momento de dictar sentencia y no simplemente a la fecha en que se produjo el menoscabo, toda vez que es factible que entre uno y otro instante la materialización del perjuicio sufra alguna variación o que sus efectos se extiendan en el tiempo.

Lo anterior por cuanto los efectos de los dańos a la salud, por lo general, no son inmutables sino que pueden aumentar o disminuir su intensidad. Luego, si esa especie de perjuicio es susceptible de variación en el tiempo, entonces la valoración que el juez haga de ella no puede limitarse a como se manifestó al momento de su causación, sino que debe tener en consideración todas las consecuencias directas que alcance a preverse al momento de dictar sentencia (Corte Suprema de Justicia, 2012) 
O, como lo pregona la decisión en cita, puede registrarse de acuerdo con el acervo probatorio que el daño resarcible es inferior al que se alegó en los hechos y que la indemnización que se requiere es menor a la que se solicitó en las pretensiones — sea porque el perjuicio disminuyó o desapareció en el lapso que existe entre su producción y el momento de dictar sentencia, o bien porque se haya pedido más de la justa proporción- entonces el juez deberá atemperar la condena al monto que alcance el quebrando en la fecha en que se profiere el fallo.

Finalmente, en otra decisión se especificó:

En suma, se ha dicho que el juez debe interpretar la demanda en su conjunto, con criterio jurídico, pero no mecánico, auscultando en la causa para pedir su verdadero sentido y alcance, sin limitarse a un entendimiento literal, por cuanto debe trascender su misma redacción, para descubrir su naturaleza y esencia, y así por contera superar la indebida calificación jurídica que eventualmente le haya dado la propia parte demandante

Aplicada la anterior doctrina al presente asunto, para la Sala resulta evidente que al solicitar el actor que los peritos calculasen "el valor actualizado" de las instalaciones y de la rentabilidad de la actividad de la curación del tabaco, implícitamente estaba pidiendo que las condenas que eventualmente se impusieran a la parte demandada lo fueran con el correspondiente reajuste monetario. Ese es el único entendimiento lógico que puede darse a las expresiones contenidas en la demanda.

Como la sentencia impugnada no reconoció al demandante la correspondiente corrección monetaria, resulta claro que el Tribunal cometió el yerro de interpretación del libelo denunciado por el censor, que no sólo es evidente sino también trascendente, lo que impone que la sentencia sea casada con el objeto de hacer el correspondiente reconocimiento. (Corte Suprema de Justicia, 2005).

Desde otra arista, Manuel Atienza aborda una problemática a partir de los denominados "casos difíciles" tomando como punto de partida a Mac-Cormick, quien en 1978 adoptó una tipología de casos difíciles — forma de silogismo—-, de cuya actividad planteó, desde la premisa normativa, dos tipos de apuros: a) problemas de interpretación y b) problemas de relevancia. Y a partir de la fáctica, otras dos 
dificultades: c) problemas de prueba y d) problemas de calificación. Obsérvese que este planteamiento de Mac-Cormick sugiere unas inquietudes al momento de dictar la sentencia y lo que al inicio de este artículo se denominó la subsunción del supuesto fáctico de una casuística en la norma a aplicar. Sencillamente sobre ese discurrir no existe discusión por cuando la labor cotidiana del juez al enfrentar un conflicto de intereses se concentra en escoger cuál o cuáles son las reglas normativas ajustables al evento de su conocimiento, así también, si los hechos expuestos en la demanda o su réplica encajan perfectamente en el supuesto fáctico descrito por la norma, y a menudo esa actividad no es tan fácil como pareciera; al contrario, es de alta delicadeza y de mucho tino, pues de su escogencia se define la teoría del caso y de contera va a marcar los derroteros de su decisión. Incluso, pensemos que la dubitación se centra en sí, determinado hecho está o no probado o cómo debe probarse; estos son algunos de los obstáculos advertidos en el discurso judicial.

Pese lo enunciado, existen otros avatares no tenidos en cuenta por Mac-Cormick y ahí es donde Manuel Atienza critica el postulado de aquel, en la medida que perfiló los casos difíciles única y exclusivamente desde el aspecto sustantivo, marginando algunos otros puntos de relevancia (Atienza, 2013).

Continúa: "Y como la subsunción, el esquema clasificatorio, parte (como premisa mayor) de una regla de acción, no considera tampoco los supuestos en los que el juez tiene que aplicar, bien una regla de fin, o bien un principio". En consecuencia, desde allí Manuel Atienza planteó su propuesta de casos difíciles duplicando la sugerida por Mac-Cormick, pues, en su opinión, las hay procesales, de prueba, de calificación, de aplicabilidad, de validez, de interpretación, de discrecionalidad y de ponderación. Todas importantes (para los fines de este artículo solamente se abordarán algunas).

Expresó Atienza que seguramente Mac-Cormick no abordó las cuestiones procesales, porque ellas podrían estar encasilladas en otras categorías y antes de plantearse el problema de ¿cómo debe decidirse la cuestión de fondo? Empero, las cuestiones procesales son circunstancias normativas y fácticas que tienen ciertas particularidades puesto que pueden encajarse bajo determinadas categorías doctrinales: legitimación procesal, recusación, prescripción, etc. "Lo cual hace que, en definitiva, que en relación con las mismas rijan ciertos criterios interpretativos, se apliquen razones de carácter institucional, etc., todo lo cual justifica que sean tratadas con cierta autonomía 
(como ocurría - por cierto- en la tradición retórica) en relación con las de carácter sustantivo" (Atienza, 2013, p.433).

En verdad, es posible en el ordenamiento jurídico colombiano actual que cuestiones procesales influyan necesariamente en la decisión esperada con la sentencia, es más, los fallos en algún momento y bajo ciertos acordes probatorios pueden anticipar o adoptar una decisión con los mismos efectos de una sentencia — por ejemplo- en los procesos declarativos de pertenencia existe la posibilidad para el juez, cuando advierta la condición de que el bien a usucapir es de uso público (Art. 375-4. Inciso 20 CGP), de terminar el proceso de forma antelada, y si bien admite apelación, podría darse el caso de que se trate de un asunto de única instancia. $\mathrm{O}$ bien, puede acontecer que el juez abrigue la existencia de una carencia de legitimación en la causa de uno de los sujetos procesales desde los albores del acto de postulación de la demanda, pues, muy seguramente, en ese proceso — que puede tramitarse en única instancia — se dicte sentencia anticipada con fundamento en el artículo 278 del Código General del Proceso o por alguno de los otros eventos allí consignados. En fin, son cuestiones procesales que influyen en la adopción de una decisión anticipada definitoria del asunto.

En lo atinente a las cuestiones de prueba la reflexión estriba en lo que Atienza denominó "estado de causa conjetural", es decir, si ha tenido lugar un determinado hecho (del pasado) desde ciertos hechos — conocidos — del presente, se puede llegar a aquel, es lo que en el razonamiento probatorio se conoce como inducción y señaló Manuel Atienza, de cara a llegar a la sentencia, una serie de dificultades concernientes — todas ellas - a la fiabilidad de los diferentes medios de prueba, a saber: testigos, documentos, informes periciales, indicios. Además, también conciernen al aspecto normativo, institucional "y por ello el razonamiento judicial no se identifica con el del historiador", porque es labor del juez combinar el manejo racional de la prueba, de la inducción con el derecho probatorio como en torno de su sistema jurídico y ese régimen puede tener exclusiones en materia normativa que requieran un rezago de tarifa legal probatoria o, como lo denomina Manuel Atienza, "que requieran un estándar de prueba más o menos exigente”, incluso, reglas sobre cómo debe practicarse un determinado medio de prueba.

En relación con los problemas de validez que pueden ir atados a los de aplicabilidad (relevancia como los denomina Mac-Cormick) o de interpretación; en donde se ubica una determinada norma, llámese ley, reglamento, costumbre en principio, 
aplicable a una situación fáctica, la cual está conforme a los criterios establecidos en el sistema jurídico para que pueda considerarse válida. Al respecto, Atienza rotuló que esos criterios del sistema jurídico se contienen en normas constitutivas — normas que confieren poder - o en normas puramente constitutivas - como la costumbre-; en todo caso, son eventos típicos del ámbito espacial y temporal, y por qué no, cuestiones de constitucionalidad "que se le plantean a un tribunal constitucional cuando se recurre una ley por considerar que su contenido va en contra de algún derecho fundamental..." (Atienza, 2013, p. 436).

En relación con las dificultades de ponderación, adujo Atienza que en la actividad del juez se le plantean temas de aplicabilidad de principios o de reglas, manifestando que si lo que se ponderan son principios en sentido estricto, esa necesidad deriva de la existencia de una laguna normativa o de una laguna axiológica (o de la duda de si existe o no una laguna) en el nivel de las reglas. En cambio, si el objeto de ponderación son directrices, el problema que resulta es si la ponderación llevada a cabo por el legislador o por la Administración es correcta, si se efectuó sin vulnerar determinados límites, por cuanto puede acontecer, que podría llevarse a discusión si en algún caso está justificado que los jueces creen reglas a partir de simplemente directrices, vale acotar, que lleven a cabo una 'ponderación discrecional'. Por supuesto, es lo que se ha llamado ponderación entre principios, al fin y al cabo, las directrices juegan un papel en la medida de su contribución a la asignación de peso a cada uno de los elementos del balance propios de una decisión, siempre el juez opta por una u otra alternativa acorde con la convicción dada de los medios de prueba y esa ponderación debe ser expresión de discrecionalidad, trátese de reglas ora de principios.

Lo anterior son los planteamientos de estos dos autores; empero, se considera procedente discrepar de ellos en algunos aspectos notables, por supuesto. Y es que en el régimen probatorio las equivocaciones del director del proceso pueden estar a la orden del día, por cuanto son muchas cosas y de variadas gamas las que debe emprender y enfrentar. $\mathrm{Al}$ respecto, mi posición crítica con las posturas de Mac-Cormick y Manuel Atienza está en dejar por fuera las cuestiones de hecho planteadas por las partes o, en otras palabras, la existencia de casos (trama fáctica) con presencia de un verdadero problema probatorio por la dificultad en cómo se presenta, es más, podrían combinarse con las cuestiones de prueba estudiadas por este último. 
Pensemos en unos casos de dificultad probatoria. En una cirugía en la que se dejó al interior de la persona una compresa que con el pasar de los días le causó efectos nocivos en el organismo —en el argot médico se conoce como oblito quirúrgico—; esta persona tuvo varias intervenciones en épocas distintas (cesárea, recesión de quiste ovárico derecho, ligadura de una de las trompas de Falopio ante la presencia de un embarazo ectópicoy extracción de elemento extraño — compresa-). La pregunta, y por consiguiente el espacio de controversia en el proceso, es: ¡en cuál de esos tres primeros actos quirúrgicos se dejó la compresa — o campo- y de cuál de tales intervenciones (cirugías) se desencadenó el perjuicio reclamado? $\mathrm{O}$ en una paciente femenina con una serie de exámenes diagnósticos para determinar la entidad de un bulto en una de sus glándulas mamarias, tomada la muestra y enviada a patología se estableció un hallazgo maligno (cáncer); practicada la extirpación del seno, las respectivas muestras se remitieron de nuevo a patología - fueron revisadas por un patólogo distinto del que inicialmente diagnosticó la lesión cancerosa-, sin embargo, el nuevo estudio reportó que la lesión era benigna (lo cual implicaba que la extirpación del seno no era el procedimiento indicado); se reclaman perjuicios de toda índole.

Obsérvese que no son eventos de fácil digestión probatoria y no se diga que casos de tal magnitud no hacen presencia en la mesa de trabajo del juez, por el contrario, los hay mucho y de varias tonalidades (contractual, extracontractual, restitución del inmueble arrendado, responsabilidad médica, reclamación de perjuicios, pérdida de oportunidad, etc.).

El otro tema olvidado por los autores en cita son las cuestiones subjetivas del juez. Será que sus creencias espirituales, su profesión o profesiones, especialidades, gustos, apatías, ideologías, decepciones, alegrías y demás vivencias no influyen en la decisión del juez pese al andamiaje normativo, procesal, de ponderación y de aplicabilidad, entre otros.

Reflexionemos sobre uno de los ejemplos. Los procesalistas sostienen que sería una atractiva coincidencia o casualidad cuando el asunto objeto de análisis guarda relación con la ciencia, arte o técnica de la especialidad del juez (jueza) y, en el caso del elemento extraño olvidado en el cuerpo de la persona que reclama perjuicios, el instructor además de abogado es médico cirujano. ¿Será que su juicio no estará parcializado hacia la solidaridad con su gremio de médicos? ¿Tendrá mayor e ingente 
actividad, por cuanto conoce el arte de buscar la verdad? Pensemos que la esposa del juez tuvo un embarazo ectópico y a raíz de él quedó infértil y su actividad se inclina por los lados de la víctima y sus consecuencias dañinas en el acto médico (lex artis).

Evidentemente sería ilógico y utópico pensar que la parte agraviada con la sentencia ataque la decisión definitiva por los aspectos personales del juez, y ello no es lo que se quiere auscultar en este estudio, por cuanto el director del proceso, en últimas, debe ser neutral y justo; empero, es un aspecto intrínseco de la decisión — como argumentación jurídica que es-, de difícil percepción exterior, pero, en ocasiones, de marcada influencia en el fallo y por ende generatriz de miramiento — en su parte factual, normativa, de valoración y demás - con mayor ahínco, celo y rigidez por parte de un juez superior en una etapa apelativa vedada para los procesos de única instancia.

En materia de derechos fundamentales Robert Alexy, partiendo del caso Lüth (1958), estimó que en esa resolución existen tres ideas, conexas entre sí y aún vigentes. (1) El catálogo de derechos fundamentales no solo garantiza derechos de defensa, sino que también enuncia todo un sistema de normas, al decir de Alexy "función jurídico-objetiva como normas de principio decisivas de valores" o como genéricamente se les conoce como principios. Alexy, citando a Kelsen y Smed, este según el cual el catálogo de derechos es expresión de un sistema cultural de valores o bienes. (2) Los derechos fundamentales vinculan a los tres poderes como principios, al ser contemplados bajo esa índole — como principios o valores - los derechos fundamentales pueden irradiar todo el sistema jurídico y por ende pueden ser relevantes en cualquier asunto jurídico, (3) Se centra en lo que se le denominó "valor" y por ende los principios y los valores tienden a entrar en pugna; de ahí, sugiere Alexy, llevar a cabo una ponderación de bienes y esa tarea, de suyo, tiene riesgos, como equivocarse y adoptar una ponderación incorrecta llegando a vulnerar derechos fundamentales; por consiguiente, la labor de la Corte es declarar primordiales las pretensiones invocadas en la tutela jurídica frente al acto que efectuó la ponderación. Y en este sentido, concluyó Robert Alexy que de esta forma se construyó el trío compuesto por valor o principio, la fuerza expansiva y la ponderación, con el fin de atribuir validez a los derechos fundamentales en el derecho civil. Este fenómeno se entiende hoy día de un modo más preciso con la figura del derecho de protección, aplicable a todas las áreas del derecho. 
Este autor, sin duda, avizora un derecho a la tutela jurídica desde el constitucionalismo actual y por ende una constitucionalización material del orden jurídico, como un todo armónico, criterio compartido en este artículo, aunado a los atrás aludidos, por cuanto la idea sugerida, al inicio de este trabajo, es dejar de lado esa expresión a raja tabla de declive a una segunda instancia en casos de trámite de mínima cuantía, seguramente razones existen en pro o en contra. No se trata de persistir tozudamente en las labores del legislador en relación con la configuración normativa que le es propia, sino de proponer una mirada justa y protectora de los derechos de quien acude a la administración de justicia o del llamado en virtud de una pretensión, pedimento que lleva ínsito una necesidad, una reparación, una duda, una incertidumbre, un sueño o un ¿qué hago si...?, en resumen, un ideal de justicia, no como una forma para desestimar o conceder súplicas por cuanto en esos escollos habrán benefactores como detractores.

\section{ConClusiones}

La teoría de los casos difíciles constituye una pauta significativa a la hora de abrigar la posibilidad del recurso de apelación en procesos de trámite en única instancia; será allí donde el margen de error del juez puede estar a la orden del día, no por falta de conocimiento, sino porque el hilo conductor entre el deber ser y el ser se torna sumamente delgado y frágil.

La autonomía del juez en sus decisiones no es absoluta ni fácil, sus decisiones están marcadas por reglas, principios, juicios de valor y posturas filosóficas que en una determinada eventualidad resultan mal entendidas, erróneamente aplicadas o indebidamente consentidas y de contera trasgreden derechos de los autores en la atmósfera judicial, como consecuencia de ello, es completamente posible, dado el cambio de margen cuantitativo entre la presentación de la demanda y el pronunciamiento del fallo (condena de perjuicios que supera los límites de la mínima cuantía), autorizar que el superior en jerarquía revise el discurso jurídico de las partes, el análisis del juez y su decisión, a través de permitirse el recurso vertical de apelación en asuntos de mínima cuantía. 
Las decisiones de los jueces crean confianza legítima en la comunidad y permiten, en grado sumo, alcanzar la paz social. Una sociedad cree en sus jueces en la medida que sus fallos sean espejo de justicia y orden, pero ante todo, de disciplina jurídica benefactora de derechos pero también, mire con desaire e imponga castigo a los infractores.

\section{REFERENCIAS}

Alexy, R. (s.f.). Tres escritos sobre los derechos fundamentales y la teoría de los principios. . En R. Alexy, Tres escritos sobre los derechos fundamentales y la teoría de los principios. Bogotá, Colombia: Universidad Externado de Colombia.

Atienza, M. (2013). Curso de Argumentación Jurídica. Madrid: Trotta.

Bahamon X. y Gomez Y. (2017). El activismo judicial en el proceso disciplinario en Revista IUSTA, No 47, julio-diciembre 2017, pp. 143-163. Obtenido de http://revistas.usta. edu.co/index.php/iusta/article/view/3807/3746

Bonorino, P. R., \& Peña Ayazo, J. I. (s.f.). Filosofía del derecho. Bogota, Colombia.: Escuela Rodrigo Lara Bonilla. 2a Edición Aumentada.

Corte Constitucional (1994). Sentencia C-365 de 1994

Corte Constitucional (1998). Sentencia SU-747 de 1998

Corte Suprema de Justicia (2003). Sentencia de 27 de marzo de 2003

Corte Suprema de Justicia. (2005). Sentencia 19 de enero de 2005, expediente 7796

Corte Suprema de justicia (2007). Sentencia 29 de junio de 2007, expediente 44001-3103001-1993-01518-01

Corte Suprema de Justicia (2009). Casación Civil. Sentencia de 18 de septiembre de 2009, expediente 20001-3103-005-2005-00406-01)

Corte Suprema de Justicia (2012). Sentencia 18 de diciembre de 2012, expediente 0526631-03-001-2004-00172-01) 
Ezquiaga, F. J. (s.f.). Los juicios de valor en la decisión judicial. Obtenido el 7 de marzo de 2018 de file://C:/Users/PEDRO/Downloads/Dialnet-LosJuiciosDeValorEnLaDecisionJudicial-1984714\%20(1).pdf

Haba, E. (2011). Princpios, Derechos y Deberes en Revista Telemática de Filosofía del Derecho. Obtenido de http://www.rtfd.es/numero14/10-14.pdf

Huertas, O y Otros (2018). El juez de vigilancia penitenciaria en España, como referente de la ejecución penal en América Latina en Revista IUSTA. N. ${ }^{\circ}$ 48, enero-junio 2018, pp. 73-96. Obtenido de http://revistas.usta.edu.co/index.php/iusta/article/view/4087/3882

Jimenez, R. (s.f.). Una Metateoría del positivismo jurídico. Madrid, España.: Marcial Pons

Morales, H. (2015). Curso de Derecho Procesal Civil. 5a Edición. Parte General. Bogota, Colombia: Ediciones Lerner.

Tribunal Superior de Distrito Judicial (2016) -Sala Laboral-. Sentencia de 19 de septiembre de 2016, expediente 1100131 05-030-2016-00165-02)

Vargas, S. (2018). La fuerza vinculante de la jurisprudencia del Consejo de Estado en Revista IUSTA, N.o 48, enero-junio 2018, pp. 119-144. Obtenido de http://revistas.usta.edu. co/index.php/iusta/article/view/4089/3884 